\title{
Influência de Negro de Fumo Modificado com Polianilina na Estrutura de Compósitos com Poli(Fluoreto de Vinilideno)
}

\author{
Valtencir Zucolotto \\ Instituto de Física de São Carlos, USP \\ Rinaldo Gregório Filho \\ Departamento de Engenharia de Materiais, UFSCar
}

Jamshid Avlyanov

Eeonyx Corporation, Pinole, USA

Luiz H. C. Mattoso

Embrapa Instrumentação Agropecuária, São Carlos, SP

Resumo: Compósitos condutores elétricos a base de poli(fluoreto de vinilideno) (PVDF) e negro de fumo modificado com polianilina $\left(\right.$ Eeonomer $\left.^{\circledR}\right)$ foram preparados através do processamento por fusão. Resultados de reometria de torque indicaram que a presença de polianilina no negro de fumo é vantajosa ao processamento por fusão, reduzindo a viscosidade do fundido em comparação com a aditivação com negro de fumo puro. Compósitos contendo acima de $5 \%$ em peso de Eeonomer ${ }^{\circledR}$ apresentaram condutividade da ordem de $10^{-2} \mathrm{~S} / \mathrm{cm}$. Esse valor se manteve estável mesmo após tratamento térmico a $150^{\circ} \mathrm{C}$ por $170 \mathrm{~h}$ em atmosfera ambiente. Análises por calorimetria diferencial de varredura (DSC) e difração de Raios-X mostraram que o tipo e a quantidade de Eeonomer ${ }^{\circledR}$, assim como a taxa de resfriamento da amostra, podem afetar a temperatura de fusão, o grau de cristalinidade e a fase cristalina do PVDF presente no compósito.

Palavras Chave: Poli(fluoreto de vinilideno), negro de fumo, polianilina, processamento.

\section{Influence of Polyaniline-modified Carbon Black on th Morphology of Poly(vinylidene Fluoride)}

Abstract: Conductive polymeric composites of poly(vinylidene fluoride) and carbon black modified with polyaniline were prepared via melting processing. The additivation with Eeonomers ${ }^{\circledR}$ is advantageous to the melt processing of the composites reducing the melt viscosity in comparison to the additivation with pure carbon black. The composites containing above $5 \%$ wt of Eeonomer ${ }^{\circledR}$ exhibited electrical conductivity around $10^{-2} \mathrm{~S} / \mathrm{cm}$, and this value remains constant even after thermal treatment at $150{ }^{\circ} \mathrm{C}$ during $170 \mathrm{~h}$ room atmosphere. Differencial Scanning Calorimetry (DSC) and X-Ray diffraction analyses showed that composites containing the $\beta$ phase of PVDF could be obtained via quenching from the melt. It was also shown that the type and amount of Eeonomer ${ }^{\circledR}$ affect the crystallinity and the melting temperature of PVDF present in the composites.

Keywords: Poly(vinylidene fluoride), polyaniline, carbon black, melt processing.

\section{Introdução}

Poli(fluoreto de vinilideno) (PVDF) tem sido amplamente estudado devido à sua importância científica e tecnológica. As aplicações desse material são favorecidas pela facilidade de processamento na forma de filmes altamente flexíveis, com excelentes propriedades mecânicas, térmicas e ópticas, além de apresentar propriedades piro e piezoelétricas ${ }^{[1]}$. O PVDF é um polímero semicristalino, podendo apre-

Autor para correspondência: Rinaldo Gregório Fo, Departamento de Engenharia de Materiais, UFSCar, Caixa Postal: 676, CEP: 13560-970, São Carlos, SP.E-mail:gregorio@power.ufscar.br 
sentar quatro fases estruturais distintas, $\alpha, \beta, \gamma$ e $\delta$, que podem ser interconvertidas pela aplicação de energia mecânica, térmica ou elétrica ${ }^{[1]}$. Dentre essas fases, destacam-se a fase $\alpha$, não polar, por ser a mais facilmente obtida e a fase $\beta$, polar, devido à elevada atividade piro e piezoelétrica que apresenta.

O PVDF apresenta morfologia de cristalização esferulítica, onde os esferulitos são formados por regiões cristalinas lamelares, que crescem do centro para as extremidades do esferulito na direção radial, e por regiões amorfas, localizadas entre as lamelas cristalinas dos esferulitos ${ }^{[2]}$.

A possibilidade de utilização do PVDF em blendas e compósitos poliméricos condutores elétricos tem sido amplamente estudada nos ultimos anos ${ }^{[3,4]}$. Contudo, a maioria destas blendas e compósitos é produzida por métodos que não envolvem altas temperaturas, como "cast" ou "spin-coat", limitando sua aplicação sob o ponto de vista tecnológico. Neste sentido, a utilização de um novo composto condutivo preparado à base de negro de fumo e polímeros condutores, Eeonomer ${ }^{\circledR[}[5]$, torna atrativa a fabricação por fusão de compósitos poliméricos condutores, de maior interesse tecnológico. Tal versatilidade advém do fato destes compostos condutivos apresentarem maior estabilidade térmica que a dos polímeros condutores isolados. No presente trabalho é apresentado um estudo da influência do tipo e quantidade do composto condutivo Eeonomer ${ }^{\circledR}$ no processamento de compósitos com o PVDF, assim como no grau de cristalinidade e na formação das fases $\alpha$ e $\beta$ desse polímero. Resultados oriundos de caracterizações elétrica e térmica dos compósitos são também apresentados e discutidos.

\section{Experimental}

\section{Materiais}

O PVDF ( Foraflon ${ }^{\circledR} 4000$ HD) foi fornecido pela Atochem e utilizado como recebido. Os compostos condutivos Eeonomer ${ }^{\circledR}$, produzidos via polimerização in situ da polianilina (PANI) sobre partículas de negro de fumo (NF), foram fornecidos pela Eeonyx Co. $\mathrm{Na}$ Tabela 1 são ilustrados os Eeonomers ${ }^{\circledR}$ utilizados e suas características.

\section{Preparação dos Compósitos}

Compósitos condutores na forma de filmes foram preparados em duas etapas: processamento no reômetro HAAKE e subsequente prensagem a quen-
Tabela 1. Características dos Eeonomers ${ }^{\circledR}$ utilizados na fabricação dos compósitos.

\begin{tabular}{ccc}
\hline Eeonomer ${ }^{\circledR}$ & $\begin{array}{c}\text { \% de PANI } \\
(\text { em peso })\end{array}$ & $\begin{array}{c}\text { Área Superficial específica } \\
\left(\mathbf{m}^{2} / \mathbf{g}\right)\end{array}$ \\
\hline KP0 & 0 & 1400 \\
KP01 & 1 & 1200 \\
KP05 & 5 & 800 \\
KP10 & 10 & 700 \\
KP15 & 15 & 600 \\
KP20 & 20 & 570 \\
KP40 & 40 & 400 \\
\hline
\end{tabular}

te na forma de filmes finos. Inicialmente os Eeonomers ${ }^{\circledR}$ foram secos em estufa a $125^{\circ} \mathrm{C}$ por $1 \mathrm{~h}$ e então incorporados ao PVDF a temperaturas entre 170 e $200{ }^{\circ} \mathrm{C}$ por $10 \mathrm{~min}$ e $80 \mathrm{rpm}$, promovendo a completa mistura dos materiais. Após o processamento no HAAKE, os compósitos foram prensados em prensa hidráulica a $180{ }^{\circ} \mathrm{C}$ sob pressão de $138 \mathrm{kgf} / \mathrm{cm}^{2}$, resultando em filmes homogêneos com espessuras entre 100 e $200 \mu \mathrm{m}$. Medidas de condutividade elétrica dc foram realizadas utilizando o método de 2 pontas $^{[6]}$. Análises termogravimétricas (TGA) foram aplicadas ao estudo da estabilidade térmica dos compósitos. Foi utilizado um equipamento Netzsch-TG 209, entre a temperatura ambiente e $800{ }^{\circ} \mathrm{C}$, com taxa de aquecimento de $10^{\circ} \mathrm{C} / \mathrm{min}$, em atmosfera dinâmica de argônio. Análises de calorimetria diferencial de varredura (DSC) foram realizadas em um equipamento Du Pont - 2910, desde a temperatura ambiente até $350^{\circ} \mathrm{C}$, com taxa de aquecimento de $10^{\circ} \mathrm{C} / \mathrm{min}$, com $\mathrm{N}_{2}$ como gás de arraste. As análises de difração de Raios- $X$ foram realizadas em um equipamento Rigaku Rotaflex, mod. RU 200 B.

\section{Resultados e Discussão}

\section{Processamento e Caracterização dos Compósitos}

O comportamento reológico dos compósitos durante o processamento no HAAKE é ilustrado na Figura 1. São apresentadas curvas de torque para compósitos com $20 \%$ em peso de Eeonomers ${ }^{\circledR}$ contendo diferentes quantidades de polímero condutor (PANI) em sua formulação. Verificou-se uma diminuição dos valores finais de torque com o aumento da quantidade de PANI no composto condutivo. Este efeito mostra que a incorporação de PANI ao negro 


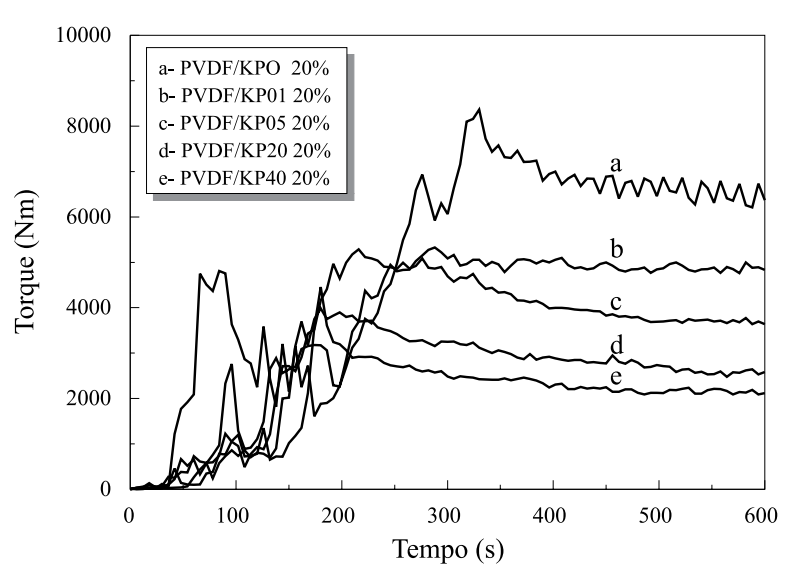

Figura 1. Curvas de torque $\mathrm{x}$ tempo para os compósitos de PVDF com $20 \%$ em peso de Eeonomers ${ }^{\circledR}$ contendo diferentes quantidades de PANI em sua formulação.

de fumo é vantajosa, proporcionando maior facilidade no processamento.

A diminiuição do torque com a adição de PANI nos compostos é atribuída à diminuição da quantidade de NF efetiva no compósito e, também, à diminuição da área superficial específica (Tabela 1), causada pela incorporação da PANI ao NF, resultando em uma menor viscosidade do fundido. A forte influência da PANI nos valores do torque é evidenciada pela queda de aproximadamente $25 \%$ do torque final com a adição de apenas $1 \%$ de PANI ao Eeonomer ${ }^{\circledR}$ (compósito PVDF/KP01, em comparação ao PVDF/KP0).

Na Figura 2 são ilustrados os resultados obtidos por TGA. Uma perda de massa em dois estágios foi verificada tanto para os compósitos como para o PVDF puro. Foi verificado ainda, que a temperatura de início de degradação do PVDF puro é ligeiramente maior que a dos compósitos. No compósito PVDF/

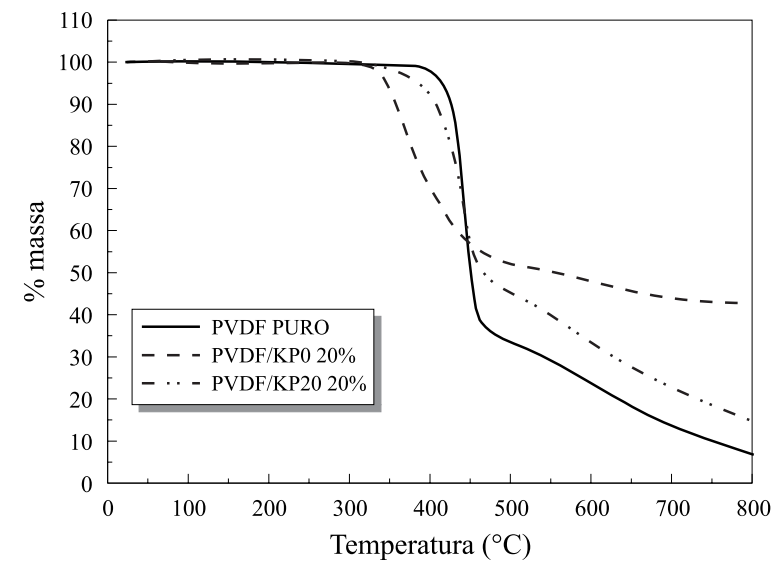

Figura 2. Curvas termogravimétricas do PVDF puro e dos compósitos $\mathrm{PVDF} / \mathrm{KP} 0$ e PVDF/KP20, todos contendo $20 \%$ em peso de Eeonomer ${ }^{\mathbb{B}}$
$\mathrm{KP} 0$, o primeiro estágio, referente à perda de massa mais acentuada, ocorreu entre 330 e $450{ }^{\circ} \mathrm{C}$ (pico da derivada primeira em $363^{\circ} \mathrm{C}$ ), ao passo que para o compósito $\mathrm{PVDF} / \mathrm{KP} 20$, o primeiro estágio ocorreu em temperaturas maiores, entre 370 e $480{ }^{\circ} \mathrm{C}$ (com pico da derivada primeira em $442{ }^{\circ} \mathrm{C}$ ).

A maior estabilidade térmica apresentada pelo compósito produzido com negro de fumo modificado com PANI (PVDF/KP20), em relação ao compósito $\mathrm{PVDF} / \mathrm{KP} 0$, é atribuída à presença da PANI no processo de degradação térmica do $\mathrm{PVDF}^{[7]}$. Em atmosfera inerte, os principais produtos formados nesse processo são o ácido fluorídrico (HF), monômeros e dímeros do tipo $\mathrm{C}_{4} \mathrm{H}_{3} \mathrm{~F}_{3}$. É provável que a PANI contida no Eeonomer ${ }^{\circledR} \mathrm{KP} 20$ atue na absorção do HF resultante da decomposição térmica do PVDF, auxiliando na estabilidade térmica do compósito.

\section{Propriedades Elétricas dos Compósitos}

Condutividade elétrica da ordem de $10^{-2} \mathrm{~S} / \mathrm{cm}$ foi verificada para os compósitos com $20 \%$ em peso de composto condutivo, independente da quantidade de PANI nele contida. A estabilidade térmica dessa condutividade em atmosfera ambiente é ilustrada na Figura 3. Observa-se que a condutividade elétrica sofre pequena alteração quando os compósitos são submetidos à alta temperatura $\left(150^{\circ} \mathrm{C}\right)$, tanto para os compósitos à base de negro de fumo puro (PVDF/ KP0) quanto para os compósitos produzidos com o Eeonomer ${ }^{\circledR}$ com $20 \%$ de PANI (PVDF/KP20). O decréscimo da condutividade normalizada $\left(\sigma_{t} / \sigma_{0}\right)$ foi in-

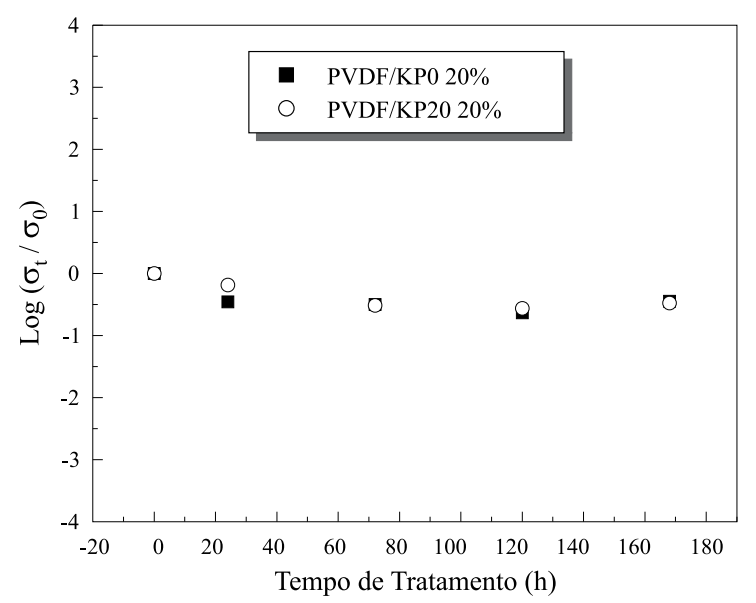

Figura 3. Estabilidade da condutividade elétrica dos compósitos PVDF/KP0 e PVDF/KP20, ambos com composição de $20 \%$ em peso de Eeonomer ${ }^{\circledR}$. Os compósitos foram mantidos a $150^{\circ} \mathrm{C}$ em atmosfera ambiente. $\sigma_{\mathrm{t}}=$ valor da condutividade no tempo $t ; \sigma_{0}=$ valor da condutividade inicial. 
ferior a uma ordem de grandeza, mesmo após cerca de 170 horas de tratamento a $150{ }^{\circ} \mathrm{C}$. É importante citar que para blendas produzidas a partir de PVDF/ Poli(o-methoxianilina) (POMA) ${ }^{[8]}$, foi verificado um decréscimo de 4 ordens de grandeza na condutividade normalizada após $170 \mathrm{~h}$ de tratamento nas mesmas condições experimentais.

Sabe-se que para compostos carregados com partículas condutivas, o incremento na condutividade não ocorre de maneira linear ${ }^{[9]}$. Inicialmente, a condutividade é pouco afetada pelo carregamento, mas aumenta drasticamente quando se atinge uma determinada concentração de carga na matriz polimérica. Essa concentração crítica, conhecida como limite de percolação, pode ser visualizada através de curvas de percolação da condutividade em função da quantidade de carga adicionada à matriz. Curvas de percolação foram obtidas utilizando-se o método de 2 pontas para determinação da condutividade elétrica. Tal estudo teve por objetivo verificar a influência do tamanho e homogeneidade dos esferulitos do PVDF na condutividade elétrica dos compósitos, uma vez que os Eeonomers $^{\circledR}$, localizados nas regiões amorfas do PVDF, poderiam estar no interior dos esferulitos (regiões interlamelares) ou entre estes ( regiões interesferulíticas). Compósitos contendo PVDF como matriz, quando resfriados rapidamente a partir do fundido apresentam esferulitos menores e pouco homogêneos, ao passo que quando resfriados lentamente ou cristalizados a elevada temperatura, tendem a apresentar esferulitos maiores e mais homogêneos. Desta maneira, os caminhos condutores formados pelas partículas interconectadas do Eeonomer ${ }^{\circledR}$, responsáveis pela condutividade do compósito, só serão afetados pelo tamanho e homogeneidade dos esferulitos se estiverem localizados nas regiões interesferulíticas. Neste caso, a condutividade elétrica dos compósitos também será afetada. A Figura 4 ilustra as curvas de percolação para o compósito PVDF/KP0. A fim de se obter diferentes tipos de morfologias, os filmes foram inicialmente fundidos a $220{ }^{\circ} \mathrm{C}$ por 15 min e em seguida resfriados de duas maneiras diferentes: i) em banho de gelo e ii) mantidos na estufa a $155^{\circ} \mathrm{C}$ por $3 \mathrm{~h}$ e em seguida resfriados à temperatura ambiente.

$\mathrm{Na}$ figura pode ser observado um limite de percolação entre 1 e $5 \%$ do composto condutivo. Pode-se observar ainda que não há influência significativa do tipo de resfriamento, e consequentemente

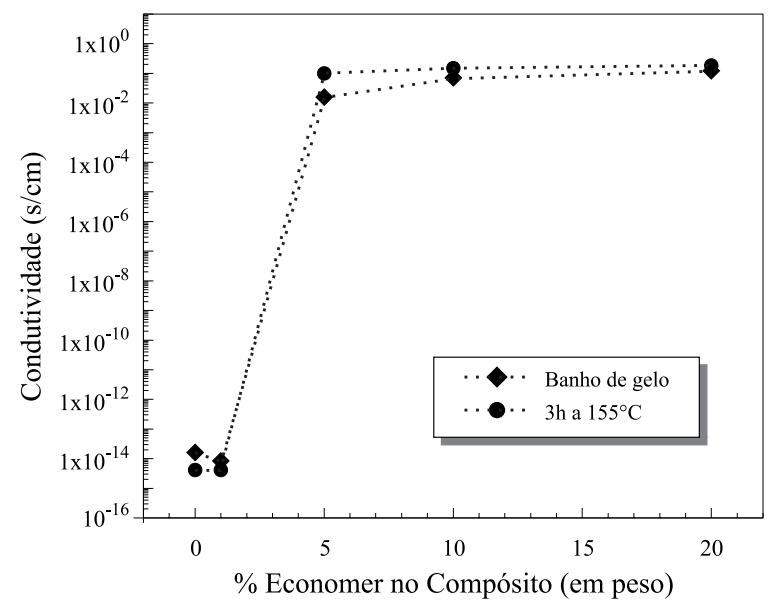

Figura 4. Condutividade elétrica de dos compósitos PVDF/KP0 com várias composições submetidos a duas diferentes condições de resfriamento.

do tamanho dos esferulitos, na condutividade elétrica dos compósitos, evidenciando que as partículas de Eeonomer ${ }^{\circledR}$ devem estar localizadas no interior dos esferulitos, nas regiões interlamelares.

\section{Influência do Composto Condutivo na Temperatura de Fusão e Grau de Cristalinidade do PVDF.}

A Figura 5 ilustra a influência da quantidade do Eeonomer ${ }^{\circledR} \mathrm{KP0}$ (somente NF) na temperatura de fusão cristalina (Tm) do PVDF. Os valores de Tm foram obtidos nos pontos de máxima intensidade das endotermas das curvas de DSC.

Uma redução da Tm pode ser observada em função do aumento da quantidade de negro de fumo nos compósitos. Este fato deve estar relacionado à espessura lamelar da parte cristalina do PVDF: esferulitos formados por lamelas mais espessas tendem a fundir em temperaturas maiores que aqueles contendo

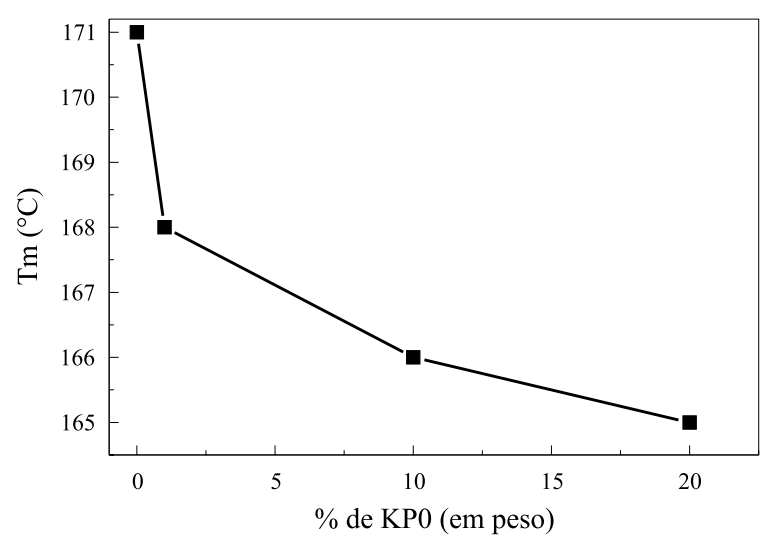

Figura 5. Influência da porcentagem de negro de fumo (KP0) na temperatura de fusão do PVDF. Os valores de Tm correspondem a máxima intensidade da endoterma. 


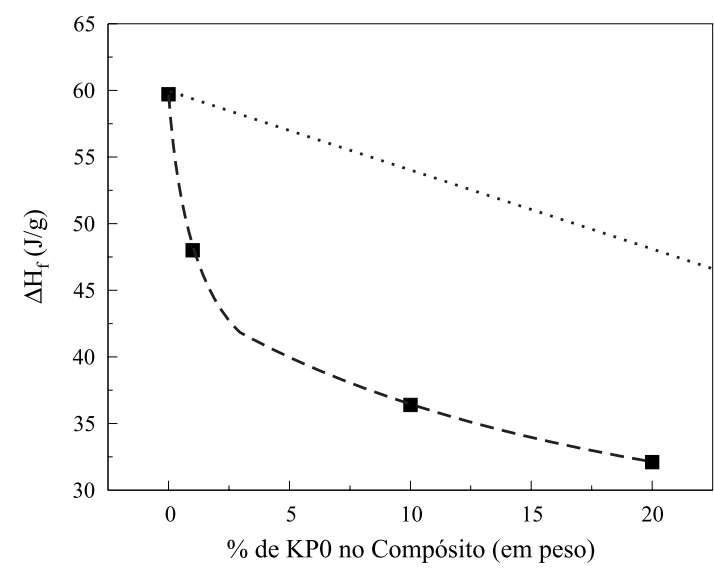

Figura 6. Variação da entalpia de fusão em função da porcentagem de negro de fumo (KP0) presente no compósito.

lamelas menos espessas. Isto sugere que a adição do negro de fumo ao PVDF influencia em sua cristalização, promovendo a formação de lamelas menos espessas. Este efeito torna-se mais acentuado com o aumento da quantidade de NF no compósito.

Além da diminuição da Tm, a incorporação do negro de fumo ao PVDF causa uma redução real de sua porcentagem cristalina, como pode ser verificado na Figura 6, onde são plotadas as entalpias de fusão $\left(\Delta \mathrm{H}_{\mathrm{f}}\right)$, correspondentes às endotermas de fusão cristalina do PVDF nos compósitos a base de KP0. Se a variação de $\Delta \mathrm{H}_{\mathrm{f}}$ com o aumento da porcentagem de Eeonomer ${ }^{\circledR}$ correspondesse à redução porcentual de PVDF nos compósitos, ela seria linear, como ilustrado na figura 6 pela linha pontilhada. Entretanto, os valores obtidos mostram uma forte redução da porcentagem cristalinina do PVDF com o aumento da quantidade de Eeonomer ${ }^{\circledR}$.

Foi investigada, também, a influência da quantidade de polímero condutor (PANI) presente no Eeonomer ${ }^{\circledR}$ nas transições térmicas dos compósitos. A Figura 7 ilustra as curvas de DSC obtidas para o PVDF puro e para três compósitos com $20 \%$ em peso de Eeonomers ${ }^{\circledR}$ contendo diferentes porcentagens de PANI. Os filmes, logo após a etapa de prensagem, foram inicialmente fundidos a $220^{\circ} \mathrm{C}$ por $10 \mathrm{~min}$, mantidos a $155^{\circ} \mathrm{C}$ por $3 \mathrm{~h}$ e em seguida resfriados até a temperatura ambiente. Tal procedimento teve por objetivo destruir a história térmica das amostras, permitindo que todas cristalizassem em semelhantes condições.

$\mathrm{Na}$ Figura 7, na curva de DSC referente ao PVDF puro (curva d), são observadas 3 endotermas de fusão cristalina. Aquela com máximo em $172{ }^{\circ} \mathrm{C}$ corresponde à fusão da fase $\alpha$ que cristalizou durante

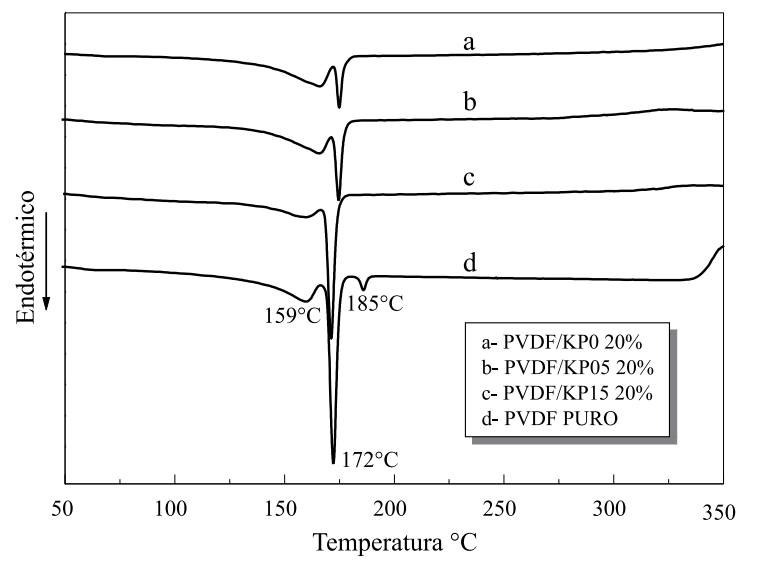

Figura 7. Curvas DSC do PVDF puro e dos compósitos PVDF/KP0, PVDF/KP05 e PVDF/KP15.

as $3 \mathrm{~h}$ em que o filme permaneceu a $155^{\circ} \mathrm{C}$. A alta definição do pico indica a presença de cristais mais homogêneos e o maior valor da Tm indica lamelas mais espessas. A endoterma a $185^{\circ} \mathrm{C}$ corresponde à fusão de uma pequena quantidade da fase $\gamma$, originada pela transformação no estado sólido $\alpha \rightarrow \gamma$, que ocorre a elevada temperatura ${ }^{[10]}$. A endoterma mais larga, com máximo em $159^{\circ} \mathrm{C}$, corresponde a fusão da fase $\alpha$ que cristalizou durante o resfriamento da amostra, de $155^{\circ} \mathrm{C}$ à temperatura ambiente. A maior largura da endoterma e o menor valor da Tm indicam, respectivamente, cristais menos homogêneos e lamelas menos espessas.

Nas curvas de DSC dos compósitos, as duas endotermas correspondentes à fusão da fase $\alpha$ cristalizada em diferentes condições permanecem. Porém, a endoterma correspondente a fusão dos cristais formados a $155^{\circ} \mathrm{C}$ tem sua intensidade drasticamente reduzida com a diminuição da porcentagem de PANI no Eeonomer ${ }^{\circledR}$ (ou aumento da porcentagem de NF). Esses resultados indicam uma redução na quantidade de cristais formados durante as $3 \mathrm{~h}$ em que a amostra permaneceu a $155^{\circ} \mathrm{C}$ e que essa redução aumenta com a porcentagem de NF no compósito. Isto significa que o NF reduz a taxa e/ou a temperatura de cristalização da fase $\alpha$ do PVDF e, consequentemente, a porcentagem cristalina, como já verificado pela diminuição de $\Delta \mathrm{H}_{\mathrm{f}}$. Além disso, o NF parece inibir a transformação no estado sólido $\alpha \rightarrow \gamma$. Um fato interessante nesta análise, como será mostrado a seguir, é que essa redução na taxa de cristalização da fase $\alpha$, provocada pelo NF presente no Eeonomer ${ }^{\circledR}$, aliada uma elevada taxa de resfriamento dos compósitos a partir do fundido, pode promover a cristalização da fase $\beta$ do PVDF. 
Influência do Eeonomer ${ }^{\circledR}$ na cristalização das fases $\alpha$ e $\beta$ do PVDF

A figura 8 mostra os difratogramas de Raios-X do PVDF puro (no alto a direita) e de quatro compósitos com diferentes quantidades de PANI no Eeonomer ${ }^{\circledR}$. Todas as amostras analisadas foram obtidas por processamento no HAAKE e posterior prensagem a $180^{\circ} \mathrm{Ce} 138 \mathrm{Kgf} / \mathrm{cm}^{2}$, não sofrendo qualquer tratamento térmico posterior. $\mathrm{O}$ difratograma referente ao filme de PVDF puro mostra que este se encontra na fase $\alpha$, apresentando picos cristalinos em $2 \theta$ iguais a 17,$5 ; 18,4 ; 20$ e $26,5^{\circ}$, característicos dessa fase. Pode-se notar nos compósitos uma diminuição da intensidade desses picos com a redução da quantidade de PANI presente no Eeonomer $^{\circledR}$ (e o consequente aumento da quantidade de NF ). Simultaneamente observa-se o aparecimento de um novo pico, em torno de $20,8^{\circ}$, característico da fase $\beta$ do PVDF, melhor definido no compósito com negro de fumo não modificado ( $\mathrm{PVDF} / \mathrm{KP} 0$ ).

Tais resultados sugerem que a formação da fase $\beta$ a partir do fundido nos compósitos é influenciada pela quantidade de NF no Eeonomer ${ }^{\circledR}$, sem a influência significativa da PANI. Através das análises por difração de Raios-X foi verificada, também, a influência da taxa de resfriamento e da quantidade do Eeonomer ${ }^{\circledR}$ KP0 na formação da fase $\beta$ dos compósitos. Para tal, os compósitos de PVDF/KP0 com diferentes composições foram fundidos a $220{ }^{\circ} \mathrm{C}$ e, em seguida, resfriados com diferentes taxas de resfriamentos. No primeiro caso os compósitos foram resfriados à temperatura ambiente e, no segundo caso, imersos em nitrogênio líquido.

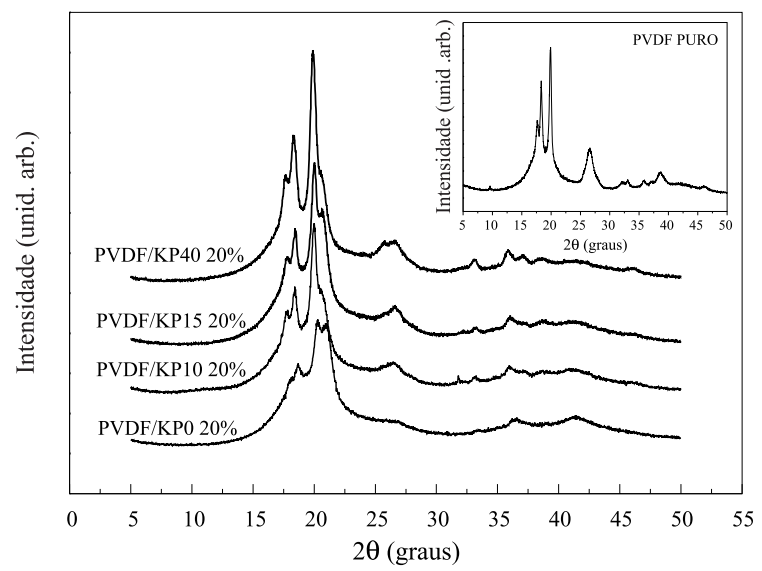

Figura 8. Difratogramas de Raios-X para os filmes de PVDF puro (canto superior) e para os compósitos produzidos com Eeonomers ${ }^{\circledR}$ com diferentes quantidades de PANI em sua formulação.

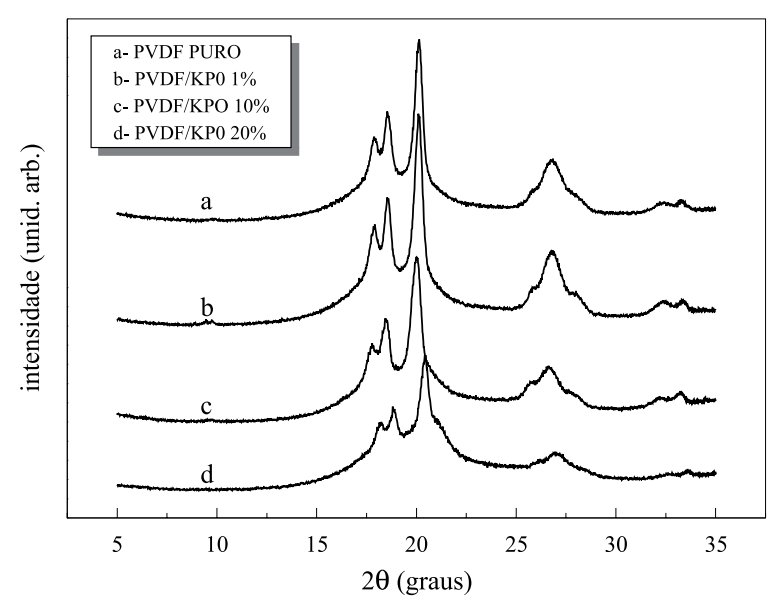

Figura 9. Difratogramas de Raios-X dos compósitos PVDF/KP0 com diferentes composições, resfriados à temperatura ambiente.

Para todos os compósitos resfriados à temperatura ambiente (Figura 9), não houve a formação da fase $\beta$. Os picos presentes, todos característicos da fase $\alpha$, apenas tiveram suas intensidades um pouco reduzidas com o aumento da porcentagem do Eeonomer ${ }^{\circledR}$, novamente indicando uma redução da cristalinidade do PVDF. Os difratogramas referentes aos compósitos resfriados em nitrogênio líquido são mostrados na Figura 10. Pode-se observar que, neste caso, houve uma mais forte redução dos picos correspondentes a fase $\alpha$ com o aumento da porcentagem de NF e o aparecimento do pico correspondente à fase $\beta$ para o compósito com $20 \%$ de KP0. Trabalhos anteriores ${ }^{[1]}$ relatam que a obtenção da fase $\beta$ do PVDF a partir do fundido só foi possível sob uma taxa de resfriamento muito elevada, só obtida para amostras muito finas $(<5 \mu \mathrm{m})$ resfriadas em nitrogênio líquido. Isto ocorre devido ao fato do PVDF ser um bom isolante térmico, o que causa uma diminuição da taxa de resfriamento efetiva no

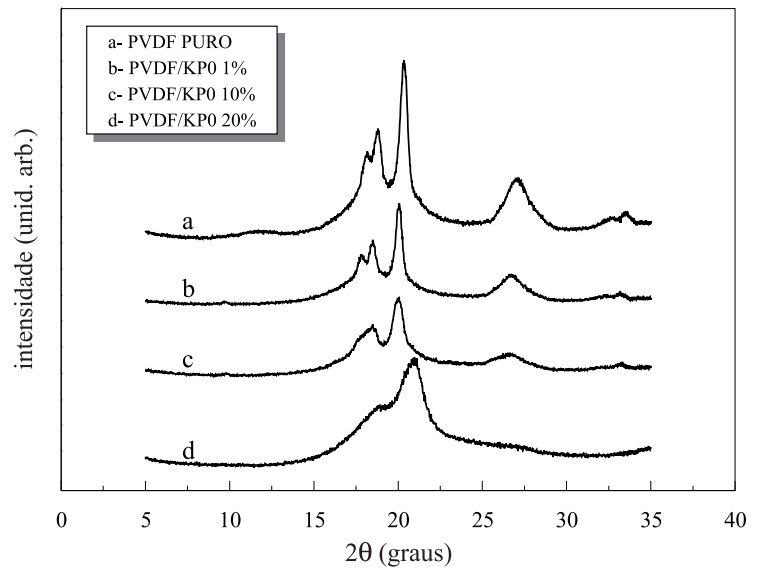

Figura 10. Difratogramas de Raios-X dos compósitos PVDF/KP0 com diferentes composições, resfriados em nitrogênio líquido. 
interior da amostra com o aumento da espessura. Taxas de resfriamento menores resultam em amostras predominantemente na fase $\alpha$, devido a elevada taxa de cristalização dessa fase em torno de $140{ }^{\circ} \mathrm{C}$, que impede a formação da fase $\beta$, cuja máxima taxa de cristalização se encontra em torno de $60{ }^{\circ} \mathrm{C}^{[12]}$. Os resultados obtidos mostram que a presença do NF de fato reduz a taxa de cristalização da fase $\alpha$ do PVDF, permitindo a formação da $\beta$ a partir do fundido nos compósitos resfriados em nitrogênio líquido, mesmo para filmes relativamente espessos ( 100-200 $\mu \mathrm{m})$.

\section{Conclusões}

Nos compósitos condutores produzidos pela incorporação de Eeonomers ${ }^{\circledR}$ ao PVDF a presença da PANI facilita o processamento e proporciona maior estabilidade térmica ao material, quando comparado aos compósitos PVDF/NF. Esses compósitos apresentam ainda uma condutividade elétrica termicamente mais estável que compósitos PVDF/POMA. Nos compósitos PVDF/Eeonomers ${ }^{\circledR}$ as partículas condutoras devem se localizar nas regiões interlamelares, no interior dos esferulitos formados pela matriz polimérica. A incorporação do Eeonomers ${ }^{\circledR}$ reduz a porcentagem de cristalinidade e a taxa de cristalização da fase $\alpha$ do PVDF, permitindo a formação da fase $\beta$ nesse polímero quando o compósito é resfriado em nitrogênio líquido a partir da fusão. $O$ negro de fumo presente no Eeonomer $^{\circledR}$ mostrou ser o principal responsável por esse resultado.

\section{Agradecimentos}

Os autores agradecem o apoio financeiro da FAPESP e do CNPq.

\section{Referências Bibliográficas}

1. Lovinger, A. J. - Poly(vinylidene fluoride) In:. Developments in Crystalline Polymers, D. C. Basset Ed.; London, Applied Science Publisher, P. 195 (1982).

2. Broadhurst, M. G.; Davis, G. T.; McKinney, J. E.; Collins, R. E. - J.Appl. Phys. 49, 4992 (1978).

3. Rocha, I. S.; Mattoso, L. H. C.; Malmonge, L. F.; Gregório Fo , R. - J Polym Sci Pol Phys 37: (12) 1219 (1999).

4. Mattoso, L. H. C.; Malmonge, L. F. - Polymer 40, 513 (1999).

5. Avlyanov, J. K. - Synthetic Metals, 102: (1-3) 1272 (1999).

6. Zucolotto, V. - Dissertação de Mestrado, Universidade Federal de São Carlos (1997).

7. Zulfiqar, S.; Zulfiqar, M.; Rizvi, M.; Munir, A.; McNeil, I. C. - Polymer Degradation and Stability, 43, 423 (1994).

8. Malmonge, L. F.; Mattoso, L. H. C. - Polymer, 41, 8387 (2000).

9. Wessling, B. - "Dispersion as The Key to Processing Conductive Polymers", In: Handbook of Conducting Polymers, Skothein, T.A., Elsenbaumer, R.L., Reynolds, J.R. (Ed). Marcel Dekker Inc., New York 467 (1998).

10. Gregorio F ${ }^{\circ}$., R.; Capitão, R. C. - J. Materials Science 35: (2) 299 (2000).

11. Yang, D.; Chen, Y. - Journal of Material Science Letters 6, 599 (1987).

12. Gregorio $\mathrm{F}^{\mathrm{o}}$., R.; Cestari, M. - J. Polim. Sci.: B: Polym. Phys. 32, 859 (1994).

Recebido: 10/08/01

Aprovado: 20/06/02 